\title{
Does the Curriculum of a Bachelor Program in International Business Meet the Competency Requirements of Internationalizing SMEs?
}

\section{A Study toward the Integration of International Relation Competency in an International Business Curriculum}

\author{
Louise B. van Weerden ${ }^{1} \&$ Peter C. van der Sijde
}

${ }^{1}$ Associate Professor SMEs in International Business, Saxion University of Applied Sciences, the Netherlands

${ }^{2}$ Professor of Organization, Entrepreneurship and Technology, Faculty of Science, Business \& Innovation and the Faculty of Social Science (Department of Organization Sciences), VU University Amsterdam, the Netherlands

Correspondence: Louise van Weerden, Associate Professor SMEs in International Business, Saxion University of Applied Sciences, the Netherlands.

Received: June 23, 2020

doi:10.5430/ijhe.v9n5p240
Accepted: August 1, 2020

Online Published: August 3, 2020

\begin{abstract}
This paper contributes to the research on discrepancy between employers' needs and graduates' competencies acquired at bachelor education. Given the fact that internationalizing SMEs have considered international relation competency (IRC) to be the key competency for starting export professionals, this qualitative study examines whether this key competency with its selected knowledge, skills and attitudes has been integrated into the curriculum of a bachelor program in International Business at a Dutch University of Applied Sciences. Based on a document analysis of this bachelor program and interviews with lecturers and alumni of this program, we found that the training of international relationship competency is almost absent in the curriculum. Both lecturers and alumni envision skills and attitude development to be incorporated into the curriculum of this internationally oriented bachelor program. The findings offer some suggestions for further research concerning developing cooperation between business and education and the assessment of international relation competency within the context of IB education.
\end{abstract}

Keywords: international relation competency, international business education, curriculum development

\section{Introduction: Relevance and Reason}

The more international and competitive economic trade becomes, the more companies will need globally competent export professionals to help them stay ahead of global competition. This type of professional is an expert in international marketing and management who, as a bilingual team player, excels in setting up and maintaining international relationships with potential business partners and stakeholders in other countries (Vonk, 2006). These qualifications relate to the export professionals' interaction and personal adjustment and are translated into the framework of international relation competency (Figure 1), which reflects the specific dimensions of functional knowledge, communication and language skills and the attitudes social initiative, open-mindedness and cultural empathy (Van Weerden \& Wijnen-Meijer, 2019). To operate effectively in their first international job after graduation, it is therefore important that students be given the opportunity during their bachelor's degree program to acquire this knowledge as well as these skills and attitudes, which pertain to international relation competency in various international business contexts. This study reports on the integration of IRC into a bachelor program in international business taught at a Dutch University of Applied Sciences. 


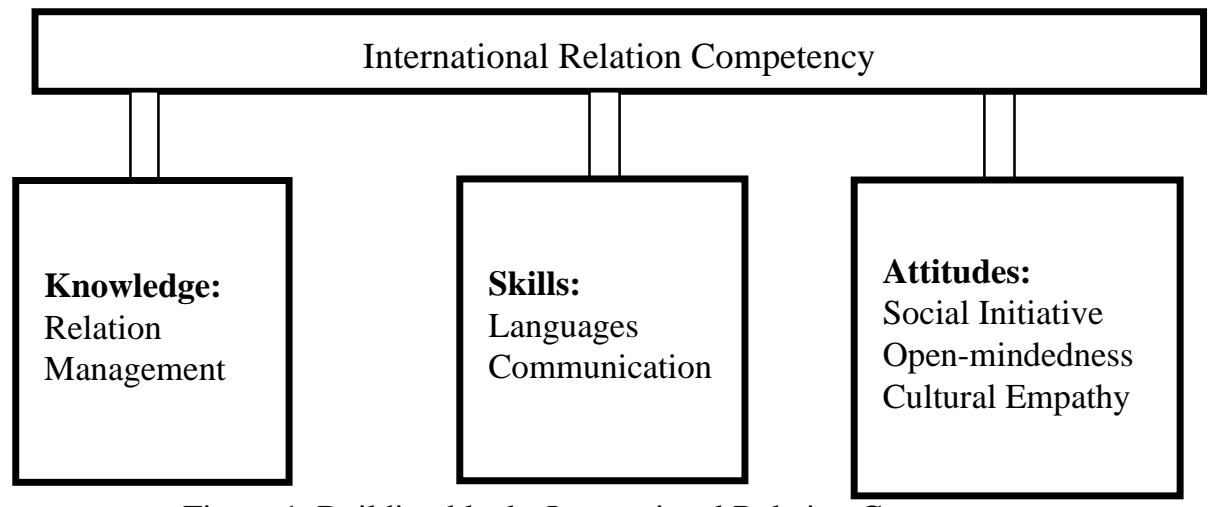

Figure 1. Building blocks International Relation Competency

\section{Competency Development}

Since competencies constitute the knowledge, skills, and attitudes that underlie successful professional performance, three factors contribute to the development of professional performance: the amount of knowledge, the number of different experiences in practice, and feedback on performance (Ericsson et al., 2006). Export professionals are experts because of their knowledge, skills and attitudes in international business, which they learn by doing (Ericsson et al., 2006). They build up their expertise to perform efficiently in a variety of export tasks such as analyzing market developments, defining an export strategy, and the operationalization of this strategy (Chassy \& Gobet, 2010). The process of expertise development has been described in various models, such as the skills acquisition model of Dreyfus (2004) that describes the importance of learning through experiences: in the first stage, the novice learns facts and rules and treats each situation as new whereas, at the last stage, the expert evaluates his actions and adjusts these to new situations. From an educational perspective, we can consider students as the novices and lecturers as experts. In their learning process, students not only acquire and expand their knowledge about specific subjects, but they also learn how to put this knowledge into practice for which they need clear instructions, reflective questions and relevant feedback from their lecturers (Kirsch, 2009; Stockard et al., 2018). Ideally, students' expertise development should combine an instructive way of teaching with acquiring experiences from practice, which enhances their confidence to start their first job after graduation (Tynjälä, 2008).

Studies on the evaluation of skills of young graduates show that teamwork, effective communication and building interpersonal relationships with people from different cultures are the very qualifications that employers value most in future managers (Hart, 2006; Davies et al., 2011). Given the crucial role of relation management for SMEs' export success (Bloemer, 2009), international relation competency underlies the successful job performance of starting export professionals. To develop this skillset, students need learning practices that enable them to develop expertise in international relation competency in international business practice. Examples of such learning practices are so-called problem-based learning (PBL) assignments based on authentic problems (Kolmos \& Egelund-Holgaard, 2017). These authentic assignments focus on the learning process of students during which they acquire knowledge and develop skills necessary to analyze and solve a given problem (Savery, 2006). For students in international business, such PBL assignments allow them to learn from international business experiences as they prepare for their future export job (Prince, 2004). During such authentic assignments, the starting export professionals realize, for instance, the impact of good communication skills only when they experience that their usual communication techniques may not work for all people in different cultural situations. When starting export professionals encounter people outside of their cultural sphere, it is imperative that they listen to the other: does the word "yes" actually means "yes" or does it follow the discussion partner's rules of politeness? And how does one interpret non-verbal signals in other cultures? In many languages, people tend not to say directly what they intend to communicate as they expect others to understand what they mean. According to Knapp-Potthoff (1997), communication skills go beyond the command of foreign language skills and knowledge about other cultures, as the interaction between individuals is often rendered more complex through cultural differences. The interaction between partners from different parts of the world requires an intercultural understanding of people to give adequate reactions (Clyne, 1994). The same applies to respecting written communication rules in international situations (Ranaut, 2018).

The challenge for the academic staff of the bachelor program in international business, therefore, is twofold: to provide theoretical knowledge on relation management and its importance for successful international business; and to develop international relation competency as the key qualification required by future employers. Moreover, the academic staff needs to create an educational environment that stimulates international relation competency 
development, ensuring a smooth transition of export professionals to their future export profession.

\section{Aim and Research Question}

The aim of this study is to examine to what extent international relation competency has a place in the curriculum of a bachelor program on international business. In addition, we also consider the role of Institutions of Higher Education in the development of this qualification. The various components of the international business curriculum may possibly contribute to the development of international relation competency. In addition to the perceptions of the lecturers on the importance and the development of international relation competency in the curriculum, we are also interested in the views of the alumni on this topic based on their experiences in their first post-graduation export job. The following research question is central in this study:

To what extent is international relation competency integrated into the curriculum of a bachelor program on international business?

To answer this research question, we will be guided by the following sub-questions:

- What are the views of lecturers and alumni on the importance of the selected knowledge, skills and attitudes of international relation competency for starting export professionals?

- What are the views of lecturers and alumni on the training of international relation competency during the bachelor program on international business?

- According to the lecturers and alumni, which knowledge, skills and attitudes of international relation competency need to be developed in professional practice?

\section{Method: Procedure}

To answer the main research question, we chose to do a mixed methods study that provides an analysis of the content and learning context in an international business curriculum. In phase 1 of this study, we analyzed the context of this study: we selected the undergraduate study International Business \& Languages (IBL) of the International Business School (formerly the School of International Management and Marketing) at a Dutch University of Applied Sciences (UAS) as this IBL program specifically trains students to become competent export professionals. Using a document study, we analyzed the main principles of Dutch UAS in relation to its implementation in the IBL curriculum. We studied documents about the IBL structure and accreditation reports and teaching materials of the IBL courses to analyze the curriculum's content, competencies and learning context regarding IRC, supplemented with information from the educational expert on the structure of the IBL program.

In phase 2 of this study, the qualitative interview study with lecturers on the integration of IRC in the IBL curriculum was complemented with a quantitative survey among IBL alumni. We conducted semi-structured interviews with the IBL program director and the selected lecturers who are teaching in the IBL program. We chose to conduct personal interviews assuming that the extra, spontaneous information and in-depth questions on specific topics might yield a better understanding of the integration of international relation competency into the curriculum. Besides, we collected the views of the IBL alumni through an online survey. To ensure content validity and to avoid words with ambiguous meanings, the questionnaire was first discussed with the IBL educational expert and piloted with three lecturers from similar education programs. The participants were asked if they had any questions or concerns about the questionnaire. This was not the case.

\section{Participants}

\subsection{Academic Staff}

For the study in phase 2, we selected the program director, the educational expert and fifteen lecturers from the IBL program from one University of Applied Sciences as the population for the interviews. Our decision to select the academic staff of only one UAS was based on the fact that these lecturers are involved in the IBL program with a specific graduate profile as export professionals. The interviewees represented a wide range of educational backgrounds: law, economics, international business, statistics, marketing, languages and human resources management. From the sixteen interviewees, six had been working in international business or export jobs prior to their current teaching in the IBL program. Some of the IBL lecturers have additional tasks such as career counseling of the students. The teaching experience of the respondents varied from 5-25 years.

\subsection{Alumni}

In addition to the perceptions of the lecturers, we collected the views of the IBL alumni regarding their experiences in 
their first post-graduation export jobs. The IBL alumni were selected from two Dutch Universities of Applied Sciences between 2011-2016, a five-year timeframe we considered to yield a robust enough contribution. The questionnaire was sent out to all 184 alumni who were registered with the two Universities of Applied Sciences between 2011-2016. From this population, 120 alumni did not respond due to reasons of wrong email address, change of jobs or relocation. With 64 respondents, the response rate was 35\%. After a careful analysis of the questionnaires, it appeared that 47 of the 64 respondents did not fill out the questionnaire properly, which made them unsuitable for this study. Therefore, the results described in this article are based on the remaining 17, and for some questions 20 respondents, who mostly graduated in 2015. The first post-graduation jobs of respondents vary from junior positions in marketing, sales and export support to start positions in communication and customer support in both SMEs and service organizations.

\subsection{Questionnaire Design Academic Staff and Alumni}

The questionnaire design for the interviews with the lecturers and the questionnaire survey for the alumni (Table 1) was set up around the dimensions of the IRC framework: functional knowledge, communication and language skills, and the attitudes social initiative, open-mindedness and cultural empathy (van Weerden \& Wijnen-Meijer, 2019). The questionnaire for the lecturers consisted of three parts. In the first part, the participants were asked about their educational and professional background and their current position with IBL. In the second part, we introduced the concept of IRC to the participants and asked each lecturer about the importance of IRC in relation to their teaching course. Finally, they were asked to give their views on the role that Institutions of Higher Education should play in the training and development of this specific competency. Each interview lasted 1-1.5 hours and was recorded and transcribed for the analysis. Whenever participants' quotes were used to illustrate the results in this article, participants were asked by the author for their permission. All participants agreed to the use of their quotes.

The questionnaire for the alumni with open-ended and closed-ended questions consisted of four parts. After some background questions in the first part, participants were asked to rank the graduates' tasks in their first international job after graduation in the second part. To capture the views of alumni on the adequacy of the IBL program concerning the development of international relation competency, they were asked to indicate the relevance of all IBL's curriculum components in the third part of the questionnaire. In the final part of the questionnaire, the alumni were asked about their views on the role that institutions of higher education should play in the acquisition of IRC. Since the alumni have different nationalities, the questionnaire was designed in English. We ensured that all data would be treated confidentially.

Table 1. Questionnaire design for the academic staff and alumni

\begin{tabular}{|c|c|c|c|}
\hline $\begin{array}{l}\text { Sub-questions of the } \\
\text { research question }\end{array}$ & Topics & Academic staff & Alumni \\
\hline \multirow[t]{8}{*}{$\begin{array}{l}\text { Views on the } \\
\text { importance of IRC }\end{array}$} & Dimensions of IRC & & \\
\hline & Functional knowledge & $\mathrm{x}$ & $\mathrm{x}$ \\
\hline & Language skills & $\mathrm{x}$ & $\mathrm{x}$ \\
\hline & Communication skills & $\mathrm{x}$ & $\mathrm{x}$ \\
\hline & Social initiative & $\mathrm{x}$ & $\mathrm{x}$ \\
\hline & Open-mindedness & $\mathrm{x}$ & $\mathrm{x}$ \\
\hline & Cultural empathy & $\mathrm{x}$ & $\mathrm{x}$ \\
\hline & $\begin{array}{l}\text { The relevance of IBL's } \\
\text { curriculum components }\end{array}$ & & $\mathrm{x}$ \\
\hline $\begin{array}{l}\text { Views on the training } \\
\text { of IRC }\end{array}$ & $\begin{array}{l}\text { The role of IRC in relation to } \\
\text { teaching courses }\end{array}$ & $\mathrm{x}$ & $\mathrm{x}$ \\
\hline $\begin{array}{l}\text { Which knowledge, } \\
\text { skills and attitudes of } \\
\text { IRC need to be } \\
\text { acquired in professional } \\
\text { practice? }\end{array}$ & & $\mathrm{X}$ & $\mathrm{x}$ \\
\hline
\end{tabular}




\subsection{Data Analysis}

For the qualitative analysis of the interviews with the IBL lecturers, we conducted a content analysis. First, we divided the interviews into segments. Next, the interviews were analyzed using an open coding process, resulting in code tree. We used a coding scheme for the themes on which basis the interview transcripts were analyzed, being the selected functional knowledge, skills and attitudes of international relation competency. During the coding process, fragments or sentences of the transcripts were coded with the 'in vivo approach'. Data analysis was supported by Dedoose software. We used descriptive statistics for the analysis of data from the alumni questionnaires. We calculated means and we established the degree of consensus among the respondents' judgments using standard deviations.

\section{Results}

\section{Phase 1: Integration of IRC in the IBL curriculum: a document analysis}

The IBL bachelor program of the selected University of Applied Sciences operates within the European, National and Institutional educational frameworks that include the European Credit Transfer and Accumulation System (ECTS). According to the ECTS requirements, bachelor programs require 240 ECTS for a completed Applied Science bachelor program. The Dutch National framework is determined by the Ministry of Education, Culture, and Science (OCW), the Accreditation Organisation of the Netherlands and Flanders (NVAO) and stakeholders such as Universities, Business Communities and the IBL National Consultative Body. The institutional framework is determined by the educational institutions and their goal is to maintain the quality of the study programs. This is done by evaluating their study programs based on the National Evaluation Framework, internal audits, theme-audits and evaluations the input of which is used to revise the curricula. Thus, the more the study programs align with these frameworks, the better the quality of these study programs will be in terms of comparison, coherence, transparency and flexibility.

\section{The IBL curriculum}

The rationale of the IBL program taught at the selected University of Applied Sciences in the Netherlands is to train students ...'to become multilingual, commercial graduates who in a culturally sensitive and confident manner bring about sustainable and successful international collaboration between people in businesses and organizations'. More precisely, IBL graduates will have the necessary competencies to build and maintain a company's international relations, particularly in the field of international purchasing, sales and account management, international communication management, and export management. Furthermore, they are able to translate these contacts into activities on a strategic, tactical and operational level. Since IBL graduates work with colleagues and customers from various countries and cultures, they have an intermediary active role focused on making use of those cultural differences for the purpose to advance the company's interests. About the importance of relation management, the IBL rationale explicitly mentions the ability of IBL students to successfully develop collaborations between people in business and organizations.

The IBL curriculum is built on the combination of economics, communication (languages and communication skills), cultures and business topics and is organized around Competencies, Themes and Projects. In addition, the curriculum focuses on three nationally defined competency areas, International Business (IB), International Communication (IC) and Intercultural Awareness (IA), which form an integral part of the graduation year. Furthermore, the curriculum is organized around 10 competencies that fall within the three competency areas (IC, IB, IA). From these 10 competencies, 7 are IBL specific competencies and the remaining 3 are UAS general competencies.

The IBL curriculum is based on the concept of competency-driven thematic project work designed to align with work practice. This means that each semester students work on a project related to a specific theme and task of their future jobs. It appears from the overview of the themes that relation management in international business is not a specific theme in the IBL curriculum. Through this project-based theme structure, students get the context for their study materials and are stimulated in the self-steering role of their competency development process. During this learning process, lecturers monitor the students' progress by stimulating students' professional development, evaluate the assignment and, finally, award the ECTS. For instance, the purpose of the theme 'Country Analysis` is that students write an export-related advisory report for an exporting company. To meet this objective, the students analyze the data on foreign markets and write up the findings in the fixed format of an export-related advisory report. The specific knowledge, skills, and attitudes needed for these steps, are acquired during the assignment and the corresponding modules.

Based on our analysis of the seven specific IBL competencies, we may conclude that international relation competency is not represented in the IBL curriculum. Although the course materials show that language and communication skills 
are integrated into the IBL curriculum, the various modules and projects of the curriculum, however, do not explicitly involve knowledge acquisition on relationship management. Moreover, the attitude dimension of international relation competency is not necessarily linked to international relation competency but is implicitly integrated with specific theme related assignments. Finally, no assessment tools specific to attitude development were found.

\section{Phase 2: Integration of IRC in the IBL curriculum: a study among the academic staff and alumni}

In this section, we describe the views of the lecturers and alumni on the importance of knowledge, skills and attitudes dimensions of international relation competency in the IBL curriculum and their views on the curricular development of international relation competency. While referring to the IBL rationale, almost all interviewees agree on the importance of building international relationships, which involve crucial competencies for students' development as future export professionals. The interviewees, however, indicate that the curriculum should be geared better towards building and maintaining relationships, the primary export task for graduates in their first export job. Therefore, the lecturers advocate for a more integrated approach of the theory and business practice to strengthen the professional profile of future export professionals.

I have the feeling that quite a few IBL graduates do not work in a specific IBL job.... When I hear what kind of jobs they get after graduation I think to myself you did not need to study IBL for that job. - Gert Willem.

Some lecturers suggest integrating ef international relation competency with the three distinct competency areas: International Business, International Communication and Intercultural Awareness.

For the IBL alumni, however, 'the realization of export orders` and 'the design of an export plan` are valued as the most important export tasks (Table 2). With regard to the first task, they reported that the acquisition of new international customers is considered the most difficult task.

Table 2. Views of importance export tasks by alumni (ranking scale: $1=$ most important and $10=$ not important at all)

\begin{tabular}{llll}
\hline & Valid N & Mean & $\begin{array}{c}\text { Standard } \\
\text { Deviation }\end{array}$ \\
\hline To realize export orders & 18 & 6.6 & 3.1 \\
To design an export plan & 18 & 6.6 & 2.3 \\
To define an international market research & 18 & 5.9 & 2.9 \\
To define an international marketing plan & 17 & 5.9 & 2.5 \\
To evaluate the foreign policy of the company & 18 & 5.7 & 2.4 \\
The maintenance of relationships with foreign business partners & 20 & 5.0 & 2.6 \\
Acquisition of new international customers / clients & 19 & 4.9 & 2.7 \\
To carry out a SWOT analysis of the company & 20 & 4.7 & 3.4 \\
To do translation services & 20 & 4.5 & 3.3 \\
Research into the satisfaction of the international customers / clients of & & & \\
the company & 20 & 4.5 & 2.7 \\
Ratings from 1 (= utmost important) to 10 (=totally unimportant) & & & \\
\hline
\end{tabular}

Concerning the importance of the functional knowledge aspects of relation management, the alumni agreed that "sharing personal information" is the most important aspect (Table 3). 
Table 3. Views of importance functional knowledge aspects of relation management by alumni (ranking scale: $1=$ most important and $10=$ not important at all)

\begin{tabular}{llll}
\hline & Valid N & Mean & $\begin{array}{c}\text { Standard } \\
\text { Deviation }\end{array}$ \\
\hline To share personal information & 18 & 6.6 & 2.0 \\
The exchange of business information & 18 & 5.1 & 1.9 \\
To check business information & 19 & 4.5 & 2.0 \\
To exchange contacts (expand network) & 19 & 4.4 & 2.4 \\
To aim for collaboration and co-creation & 19 & 4.4 & 2.1 \\
To negotiate & 19 & 4.2 & 1.8 \\
To solve problems & 18 & 3.3 & 1.7 \\
To investigate the client's needs & 18 & 2.9 & 2.5 \\
(Ratings from 1 (= utmost important) & (=totally & & \\
unimportant) & & & \\
\hline
\end{tabular}

With regard to knowledge acquisition, many interviewees believe that theories on relation management should be a prerequisite in the curriculum; without this knowledge, the future export managers have little to offer to SMEs. Relation management as input for international relation competency is hardly taught in the courses of the IBL curriculum and any discussion on this topic depends more or less on the interest of the individual teacher.

I think that students can benefit if more explicit knowledge would be given to this topic. At this moment, I think it is taught in different courses in the curriculum. [Can you expand on this?.] ... Naturally, it is part of the languages...... It could be that relation competency is discussed with the sales course. But theories? I do not know exactly what is discussed during courses and whether that is sufficient. But I do think it is a very important theme which should be discussed. - Caroline

Like the lecturers, the alumni, too, advocate for more knowledge acquisition on relation management.

Both lecturers and alumni agreed that the training in language skills is insufficient. Though alumni felt by and large that their education had prepared them adequately in the area of written communication, they found their oral communication skills to be wanting. According to the language teachers, alumni's need for more training in English and Spanish could be due to a considerable reduction in teaching hours for the benefit of modules on cultural awareness. Therefore, the language teachers advocate for an increase in language learning and hours and, preferably, the same number of hours previously allotted. For the entrepreneurs, the role of foreign languages, with English in the first place, followed by German and Spanish, remains very important for starting export professionals. This supports the increasing call of the academic staff to connect English with communication skills in all the courses and modules of the curriculum. Finally, the lecturers suggested that a long stay in a foreign country is an advantage, especially if it results in improved language skills.

We further note that the development of attitudes remains a difficult point for the academic staff as the alumni consider their attitudes towards the social initiative and open-mindedness to be less developed. This outcome is reflected in their need for more training on professional development and cultural management.

Look, I think that social initiative and open-mindedness are lagging, I am not happy with how it is integrated now into the curriculum. - Ellen

I miss cultural empathy in our program. But there should be a course on cultural communication, a course which combines cultural awareness and communication. - Suzan

The lecturers found it hard to simulate realistic situations and the assessment of student performances in those simulated situations proved difficult as well.

But instead of assessing, you can only have an opinion about open-mindedness and social initiative. Open-mindedness is difficult to assess and grade. You can't say they have grade 6 for open-mindedness. - Suzan

Both lecturers and alumni addressed the same problem that the limited time allocated to a course is spent on theory, hence leaving no room for the application of knowledge, skills and attitudes in international business practice. Lecturers provide the required exposure to the international business practice by bringing in export managers as 
guest speakers, organizing company visits, or using international case studies in the classroom. However, these efforts are limited in their ability to give students the practical experience necessary to all learning. The alumni further emphasized that active involvement of internationalizing companies in the various projects and modules could improve their professional development. Particularly, they consider that practicing the selected skills and attitudes of IRC within authentic international business contexts would enhance the development of IRC. In sum, the lecturers and the alumni share the opinion that teaching knowledge about relation management and the development of the skills and attitudes of international relation competency requires considerably more attention than is currently the case.

\section{Discussion}

Our study aimed to get a better understanding of the integration of international relation competency into the curriculum of a bachelor education program on international business. The main reason for examining this topic has been the importance that internationalizing SMEs have attached to international relation competency as the key qualification for future export professionals.

Despite its rationale, we found that the ability of IBL students to successfully develop collaborations between people in business and organizations has been underestimated in the IBL curriculum. We found that both IBL lecturers and IBL alumni agreed that this competency is only implicitly integrated into the curriculum. This is illustrated by the lack of teaching theoretical knowledge on networking and relation management as SMEs' internationalizing strategy in the curriculum of IBL. Moreover, there appears to be a variation in attributed importance among the various export tasks. Whereas the lecturers considered "building relationships" to be the most important export task, the alumni considered this the least important. For them, 'the realization of export orders` and 'the design of an export plan 'were valued as the most important export tasks. The alumni claimed that the relation management was not explicitly part of their study. As a matter of fact, they even considered the acquisition of new international customers to be the most challenging task for them.

Expanding on the findings from Bloemer (2009) about the importance of building relationships for internationalizing SMEs, this study shows that the deficiency in international relation competency by the academic staff illustrates the disconnect between education and work practice (Jackons, 2009). Although the lecturers all agree on the importance of international relation competency, it appears that they are not fully aware that internationalizing SMEs consider building relationships with potential business partners in foreign markets to be the key qualification for starting export professionals. An explanation for this limited awareness could be the IHEs' lack of structural cooperation with internationalizing SMEs. Students write their theses commissioned by companies and have their work placements, but there is little synergy between education and real-world business practice (Wilson, 2012). This mismatch could be due to the complexity of transferring knowledge from education to workplace: higher education takes the significance of their knowledge for granted but the expectation in the workplace is that the knowledge acquired is ready to use'. If this is not the case, then questions about its relevance arise (Eraut, 2004). Consequently, both education and workplace ignore the challenges of integrating acquired knowledge and skills with new situations: the development of students' skills typically takes place in work settings and is not part of their formal education (Stenström, 2006). Through UBC-based teaching (Van der Sijde, 2012), the knowledge transfer from universities to business and vice versa could well improve the cooperation between university and business.

The professional practice also constitutes an important source for attitude development since attitudes are highly personal and therefore depend on the situation and specific tasks that the international employee carries out (Von Treuer et al., 2011). This type of so-called tacit knowledge is difficult to convey in a classroom-based training program (Nonaka \& Takeuchi, 1995), which is why its acquisition is blended with the work itself through informal learning (Park \& Jacobs, 2011). If we link the alumni's limited attitude towards the social initiative and open-mindedness with their need for more practical experiences in international sales, it supports our conviction that an improvement of the development of these attitudes could positively contribute to their performance in building relationships. That said, students should be confronted with tasks from practical reality, such as working in an international team, which allows them to assume greater responsibilities with required behavior. Only in these new situations can students develop the relevant attitudes required to build international business relationships. However, the emphasis during the internships is more often than not placed on well-defined assignments, usually based on knowledge, which does not challenge the students' attitudes such as social initiative, open-mindedness, creativity or cultural empathy. As a matter of fact, the students' attitudes may well determine the success of an internship with an internationalizing company.

Another complicating factor is the lecturers' need for a validated assessment tool for the selected attitudes that would contribute to successful integration of international relation competency into the IBL curriculum. To validate 
competencies is a complex process: a competency is not homogenous and therefore not always manifested in behavior given its dependency on various contexts (Ruben, 1976). Other validation problems are the subjectivity of competency evaluations and the different contexts between work practice and education (Luken, 2006). In order to bridge the gap between a competency framework and work practice, Ten Cate and Scheele (2007) introduced the concept of trust in the validation of competencies in the medical practice. The students' ability to carry out professional activities adequately is based on so-called Entrustable Professional Activities (EPA's) that are units of professional practice that describe the work tasks: activities or responsibilities to be done in patient care in a safe manner which is entrusted only to trained clinicians. EPA's are independent of persons and define a profession whereas competencies describe persons through their knowledge, skills and attitudes. Consequently, EPA's require several domains of competencies to be developed by students. During their training, students may be entrusted with EPA's when their supervising clinicians believe they can take on these responsibilities (Ten Cate \& Scheele, 2007). Given the similar dynamics of the medical context and international business context with constantly changing contacts and (cultural) problems, it would be interesting to see if this method of competency validation from the medical practice could be applied to the validation of international relation competency in the international business practice. Further research will tell.

\section{Conclusion}

The aim of this study was to determine the extent to which international relation competency with its attitudes and skills have been represented in the curriculum of the bachelor education program International Business \& Languages. The various data collection methods used in this study are document analysis, the interviews with the teaching staff and a survey among alumni, all of which have studied the phenomenon of the integration of international relation competency in the curriculum of the IBL education program. We found that both IBL lecturers and IBL alumni agreed that this competency is only implicitly integrated into the curriculum. According to the interviewees, the development of the attitudes of international relation competency during the courses deserves a lot more attention than it currently receives. Moreover, both parties also agreed that the training and development of the selected skills and attitudes need major improvement. They recommend to actively involve internationalizing companies in some curricular components to stimulate learning from experiences. Together with supportive learning strategies and assessment, this could have a positive impact on the employability of students.

One limitation of our study was that the interviewees were selected only from one institution of higher education. However, given the similar results of equivalent studies of related studies, we believe that the findings are representative. Another limitation of the study is the relatively low response rate of the alumni survey. Although these respondents may not be representative of others, we consider their contribution valuable to support the findings of the educators. Nevertheless, future studies should try to involve more alumni to increase their results. Despite these limitations, we think that the study contributes to the existing literature about the focus of an international business curriculum concerning students' development of attitudes and skills in relation to learning from experiences.

\section{Contributions}

From a theoretical perspective, the findings of this study show that the curriculum concept of competency-driven thematic project work appears to be insufficient for the skills and attitude development of international relation competency during bachelor education. For students, the development of their skillset becomes meaningful only when it is aligned with authentic learning assignments with a PBL focus. It is, therefore, important that lecturers raise students' awareness about the actual use of their knowledge acquisition in combination with their skills and attitude development for the work practice to prepare students optimally for their first export job (Jackson, 2010; Baaken et al., 2015). The value of knowledge is vital to judge the reliability of information: the more one knows about a specific domain, the more complex the tasks one can solve, which in turn leads to enhanced learning. Strong ties between the academic staff and internationalizing SMEs could be valuable resources for exploring a combination of cultural competency, critical thinking and reflection that occur in authentic globalized environments (Gamble et al., 2010). Such engagement of the academic staff with the business might bridge the gap between education and business, and it is likely going to play a larger role, certainly in light of recent curricular development that stresses the need for work practice through authentic learning (Quintana et al., 2016). Instead of offering just occasional connections, education should return to the center of professional reality (Vonk, 2006) without, however, becoming too dependent on professional practice, and diminish education's responsibility for training students (Visscher-Voerman, 2018). Knowledge transfer is an essential task of education, and we support the suggestion of Visscher-Voerman (2018) that students would probably benefit most from traditional education combined with PBL learning formats. 


\subsection{Implications for Teaching IBL}

An important issue to emerge from the study is related to the lack both of knowledge on relation management as a prerequisite for successful international business, and of international relation competency as the key qualification of starting export professionals. To improve the quality of the IBL curriculum, this topic should become more explicit in various components. Moreover, better integration of the various curriculum modules, projects and courses would help to strengthen the professional profile of the IBL graduate. This implies that the IBL program director and the academic staff need to improve their cooperation for the benefit of the curriculum's quality.

Based on studies that describe language proficiency as a prerequisite qualification for an export manager (Hagen et al., 2006; Orgean et al., 2009), this study shows that investing in language education at IHEs is necessary for better preparation of IBL students for their first post-graduation export job. The study of Hagen (2010) illustrates that European SMEs have an increasing need, apart from the three major languages English, French and German, for Spanish, Chinese, Arabic and Portuguese. While the majority of the graduates felt that their education had equipped them with written communication skills, this was not the case when discussing the necessary level of verbal communication skills required in the international work practice. Another important issue of the study related to the alumni's need for better application of theory to international practice. They also felt that their business acumen was somewhat lacking in their first export job, particularly in relation to sales. In sum, improvements in the IBL curriculum address internal communication regarding the content and profile of the IBL professional, the command of English, and better preparation for the work field through practical work experience.

\subsection{Recommendations for Further Research}

The study offers prospects for further research. The findings of this research study illustrate the need for further research into the assessment of attitude development within the context of IB education. As described in the discussion, the EPA method of competency validation (Ten Cate, 2005) could be a relevant assessment tool. During their training, students may be entrusted with EPA's provided the team of supervising lecturers and export managers believe they can take on these responsibilities. Further research into the assessment of attitudes may be a prerequisite for the integration of IRC into the IB curriculum. Another suggestion for future studies would be to explore the integration of IRC with IB curricula taught at other UAS in the Netherlands to compare the IB curricula and lecturers' views on the relevance of IRC. This comparative research could well deliver additional relevant insights for the integration of IRC into the IB curriculum.

\section{References}

Baaken, T., Kiel, B., \& Klieuwe, T. (2015). Real World Projects with Companies Supporting Competence Development in Higher Education. International Journal of Higher Education, 4(3), 129-139. https://doi.org/10.5430/ijhe.v4n3p129

Bloemer, J. (2009). International business and communication: Een kwestie van grenzeloos relatiemanagement. University of Applied Sciences Zuyd.

Chassy, P., \& Gobet, F. (2010). Speed of expertise acquisition depends upon inherited factors. Talent Development and Excellence, 2(1), 17-27.

Clyne, M. (1994). Inter-cultural communication at work: Cultural values in discourse. Cambridge University Press. https://doi.org/10.1017/CBO9780511620799

Davies, A., Fidler, D., \& Gorbis, M. (2011). Future work skills 2020. Institute for the Future for the University of Phoenix Research Institute http://www.iftf.org/uploads/media/SR-1382A_UPRI_future_work_skills_sm.pdf

Dreyfuss, S.E. (2004). The five-stage model of adult skill acquisition. Bulletin of Science Technology \& Society, 24(3), 177-181. https://doi.org/10.1177/0270467604264992

Ericsson, K.A., Feltovich, P.J., \& Prietula, M. (2006). Studies of expertise from psychological perspectives. In K.A. Ericsson, N. Charness, R..R. Hoffman, \& P.J. Feltovich (Eds.), The Cambridge handbook of expertise and expert performance (pp. 41-68). Cambridge University Press. https://doi.org/10.1017/CBO9780511816796

Eraut, M. (2004). Informal learning in the workplace. Studies in Continuing Education, 26(2), 247-273. https://doi.org/10.1080/158037042000225245

Gamble, N., Patrick, C.-J., \& Peach, D. (2010). Internationalising work integrated learning: creating global citizens to meet the economic crisis and the skills shortage. Higher Education Research and Development, 29(5), 535-546. https://doi.org/10.1080/07294360.2010.502287 
Hagen, S., Foreman-Peck, J., Davila-Philippon, S., \& Nordgren, B. (2006). ELAN: Effects on the European economy of shortages of foreign language skills in enterprise. https://ec.europa.eu/assets/eac/languages/policy/strategic-framework/documents/ elan_en.pdf

Hagen, S. (2010). Mapping successful language use in international business: How, when and where do European companies achieve success? In G. Stickel (Eds.), Language use in business and commerce in Europe (pp. 23-34). Peter Lang.

Jackson, D. (2009). Profiling industry-relevant management graduate competencies: The need for a fresh approach. International Journal of Management Education, 8(1), 85-98. https://doi.org/10.3794/ijme.81.281

Jackson, D. (2010). An international profile of industry-relevant competencies and skills gap in modern graduates. International Journal of Management Education, 8(3), 29-58. https://doi.org/10.3794/ijme.83.288

Kirsch, D. (2009). Problem solving and situated cognition. In P. Robbins \& M. Aydede (Eds.), The Cambridge handbook of situated cognition, 264-306. Cambridge University Press. https://doi.org/10.1017/CBO9780511816826.015

Knapp-Potthoff, A. (1997). Interkulturelle kommunikationsfähigkeit als lernziel. In A. Knapp-Pothoff, \& M. Liedke (Eds.), Aspekte interkultureller kommunikationsfähigkeit, 181-205. Iudicium.

Kolmos, A., \& Egelund-Holgaard, J. (2017). Impact of PBL and company interaction on the transition from engineering education to work. In A. Guerra, F. Jose Rodriquez, A. Kolmos, \& I. Pena Reyes (Eds). Proceedings of the $6^{\text {th }}$ International Research Symposium on PBL: PBL, Social Progress and Sustainability, 87-98. Bogota: Aalborg Universitetsforlag.

Luken, T.P. (2006). Hoe meetbaar zijn competenties? Dilemma en uitweg bij het werkbaar maken van het competentiebegrip. In P. Schramade (Ed.), Handboek Effectief Opleiden, 89-108. Elsevier Human Resource.

Nonaka, I., \& Takeuchi, H. (1995). The knowledge-creating company: How Japanese companies create the dynamics of innovation. Oxford University Press. https://doi.org/10.1016/0024-6301(96)81509-3

Ogrean, C., Herciu M., \& Belascu L. (2009). Competency-based management and global competencies challenges for firm strategic Management. International Review of Business Research Papers, 5(4), 114-122.

Park, Y., \& Jacobs, R.L. (2011). The influence of investment in workplace learning on learning outcomes and organizational performance. Human Resource Development Quarterly, 22(4), 437-458. https://doi.org/10.1002/hrdq.20085

Prince, M. (2004). Does active learning work? A review of the research. Journal of Engineering Education, 93(3), 223-231. https://doi.org/10.1002/j.2168-9830.2004.tb00809.x

Quintana, C.D.D., Mora, J.-G., Pérez, P.J., \& Vila, L.E. (2016). Enhancing the development of competencies: The role of UBC. European Journal of Education, 51(1), 10-24. https://doi.org/10.1111/ejed.12162

Ranaut, B. (2018). Importance of good business writing skills. International Journal of Language and Linguistics, 5(2), 32-41. https://doi.org/10.30845/ijll.v5n2a5

Ruben, B.D. (1976). Assessing communication competency for intercultural adaptation. Group \& Organization Management, 1(3), 334-354. https://doi.org/10.1177/105960117600100308

Savery, J.R. (2006). Overview of problem-based learning: Definitions and distinctions. The Interdisciplinary Journal of Problem-based learning, 1(1), 9-20. https://doi.org/10.7771/1541-5015.1002

Stenström, M.-L. (2006). Polytechnic graduates working life skills and expertise. In P. Tynjälä, J. Välimaa, \& G. Boulton-Lewis (Eds.), Higher education and working life: Collaborations, confrontations and challenges, 89-102. Emerald

Stockard, J., Wood, T.W., Coughlin, D., \& Rasplica Khoury, C. (2018). The effectiveness of direct instruction curricula: A meta-analysis of a half century of research. Review of Educational Research, 88(4), 479-507. https://doi.org/10.3102/0034654317751919

Ten Cate, O. (2005). Entrustability of professional activities and competency-based training. Medical Education, 39(12), 1176-1177. https://doi.org/10.1111/j.1365-2929.2005.02341.x

Ten Cate, O., \& Scheele, F. (2007). Competency-based postgraduate training: Can we bridge the gap between theory and clinical practice? Academic Medicine, 82(6), 542-547. https://doi.org/10.1097/ACM.0b013e31805559c7 
Tynjälä, P. (2008). Perspectives into learning at the workplace. Educational Research Review, 3(2), 130-154. https://doi.org/10.1016/j.edurev.2007.12.001

Van der Sijde, P.C. (2012). Profiting from knowledge circulation: The gains from university- industry interaction. Industry and Higher Education, 26(1), 15-19. https://doi.org/10.5367/ihe.2012.0082

Van Weerden, L.B., \& Wijnen-Meijer, M. (2019). International competencies for European SME graduate employees. A Dutch experience. In The Routledge Companion to European Business, Routledge Taylor \& Francis Group, 200-212. https://doi.org/10.4324/9781315397306-17

Von Treuer, K., Sturre, V.L., Keele, S.M., \& McLeod, J.L. (2011). An integrated model for the evaluation of work placements. Australia Asia-Pacific Journal of Cooperative Education, 12(3), 195-204.

Visscher-Voerman, J.I.A. (2018, December 12). Perspectieven op curriculuminnovatie in het hoger onderwijs. Retrieved from https://www.techyourfuture.nl/files/downloads/Lectorale_rede_Irene_Visscher-Voerman.pdf

Vonk, F. (2006). Kleur geven aan 'internationals' in het MKB. Over competenties van 'internationals' in het MKB. HAN Business Publications, 2, 45-77.

Wilson, T. (2012). Review of business-university collaboration. Department for Business, Innovation and Skills. https://assets.publishing.service.gov.uk/government/uploads/

system/uploads/attachment_data/file/32383/12-610-wilson-review-business-university-collaboration.pdf 